Pacific Journal of Mathematics

BOUNDS FOR THE EIGENFUNCTION OF A
TWO-PARAMETER SYSTEM OF ORDINARY DIFFERENTIAL
EQUATIONS OF THE SECOND ORDER 


\section{BOUNDS FOR THE EIGENFUNCTIONS OF A TWO-PARAMETER SYSTEM OF ORDINARY DIFFERENTIAL EQUATIONS OF THE SECOND ORDER}

\section{Melvin Faierman}

In previous papers the author has shown that, in contrast to the one-parameter case, the normalized eigenfunctions of two simultaneous Sturm-Liouville systems in two parameters are not necessarily uniformly bounded. Moreover, best possible bounds for the normalized eigenf unctions were also derived. However these results were only established under the assumption that the coefficients of our differential equations satisfied certain special conditions. Hence, in order to deal with problems which often arise in physical practice, it is important to extend our results to the case where the coefficients of our differential equations satisfy more general conditions then hitherto supposed. Accordingly, it is the object of this paper to derive best possible bounds for the normalized eigenfunctions of the simultaneous two-parameter systems in question under much weaker restrictions on their coefficients than was previously assumed.

The study of the behavior of the eigenvalues and eigenfunctions of multiparameter Sturm-Liouville systems was initiated by F. V. Atkinson [1, §4] who pointed out that the theory related to this subject was still far from clear. Since the appearance of Atkinson's paper, the author has obtained some relevant results, the most important of which are contained in papers [4] and [5] mentioned above. The results given in this paper therefore constitute a further stage in the development of the theory related to this subject.

Finally we mention that the methods used in this paper are quite different from those used in [4] and [5] wherein techniques from transition point theory and the method of asymptotic integration were employed. Here our results are established by utilizing the information given in [4] and [5], by making a through study of the general character of the solutions of our differential equations, and lastly, by making use of a Sobolev type inequality.

1. The main theorem. We shall be concerned here with the simultaneous two-parameter systems

$$
\begin{aligned}
& y_{1}^{\prime \prime}+\left(\lambda A_{1}\left(x_{1}\right)-\mu B_{1}\left(x_{1}\right)+q_{1}\left(x_{1}\right)\right) y_{1}=0, \\
& 0 \leqq x_{1} \leqq 1, \quad '=d / d x_{1},
\end{aligned}
$$




$$
\begin{array}{ll}
y_{1}(0) \cos \alpha_{1}-y_{1}^{\prime}(0) \sin \alpha_{1}=0, & 0 \leqq \alpha_{1}<\pi, \\
y_{1}(1) \cos \beta_{1}-y_{1}^{\prime}(1) \sin \beta_{1}=0, & 0<\beta_{1} \leqq \pi,
\end{array}
$$

and

$$
\begin{gathered}
y_{2}^{\prime \prime}+\left(-\lambda A_{2}\left(x_{2}\right)+\mu B_{2}\left(x_{2}\right)+q_{2}\left(x_{2}\right)\right) y_{2}=0, \\
0 \leqq x_{2} \leqq 1, \quad '=d / d x_{2}, \\
y_{2}(0) \cos \alpha_{2}-y_{2}^{\prime}(0) \sin \alpha_{2}=0, \quad 0 \leqq \alpha_{2}<\pi, \\
y_{2}(1) \cos \beta_{2}-y_{2}^{\prime}(1) \sin \beta_{2}=0, \quad 0<\beta_{2} \leqq \pi,
\end{gathered}
$$

where it will be supposed that, for $i=1,2, q_{i}$ is real and continuous, and $A_{i}, B_{i}$ are real and analytic in $0 \leqq x_{i} \leqq 1$. We shall also suppose that $\Delta=A_{1} B_{2}-A_{2} B_{1} \neq 0$ in $I^{2}$ (the product of the intervals $0 \leqq x_{1} \leqq 1,0 \leqq x_{2} \leqq 1$ ). Furthermore, there is no loss of generality in assuming henceforth that the $A_{i}, B_{i}$, and $\Delta$ are all positive for all values of $x_{1}$ and $x_{2}$ in $I^{2}$, since this can always be achieved, if necessary, by introducing a nonsingular transformation in the parameters $\lambda$ an $\mu$ (see [4, Appendix A]).

Recall from [4, §2] that by an eigenvalue of the system (1-4) we mean a pair of numbers, $\left(\lambda^{*}, \mu^{*}\right)$, such that for $\lambda=\lambda^{*}$ and $\mu=\mu^{*}$, (1) and (3) have nontrivial solutions satisfying (2) and (4), respectively. If $y_{1}\left(x_{1}, \lambda^{*}, \mu^{*}\right)$ and $y_{2}\left(x_{2}, \lambda^{*}, \mu^{*}\right)$ denote these solutions, respectively, then the product, $\prod_{i=1}^{2} y_{i}\left(x_{i}, \lambda^{*}, \mu^{*}\right)$, is called an eigenfunction of the system (1-4) corresponding to $\left(\lambda^{*}, \mu^{*}\right)$. Important results pertaining to the eigenvalues and eigenfunctions of the system (1-4) were recorded in the reference just cited, and in particular it was noted that the eigenvalues were all real and could be expressed in the form $\left(\lambda_{j, k}, \mu_{j, k}\right), j, k=0,1,2, \cdots$, where, with $\phi_{i}(i=1,2)$ denoting the solution of $(2 i-1)$ satisfying $\phi_{i}(0, \lambda, \mu)=$ $\sin \alpha_{i}, \phi_{i}^{\prime}(0, \lambda, \mu)=\cos \alpha_{i}, \phi_{1}\left(x_{1}, \lambda_{j, k}, \mu_{j, k}\right)$ has precisely $j$ zeros in $0<$ $x_{1}<1$ and $\dot{\phi}_{2}\left(x_{2}, \lambda_{j, k}, \mu_{j, k}\right)$ has precisely $k$ zeros in $0<x_{2}<1$. In the sequel we shall let $\psi_{j k}^{*}\left(x_{1}, x_{2}\right)=\prod_{i=1}^{2} \phi_{i}\left(x_{i}, \lambda_{j, k}, \mu_{j, k}\right)$ and $\psi_{j, k}=$ $\psi_{j, k}^{*}\left(x_{1}, x_{2}\right) /\left\|\psi_{j, k}^{*}\right\|$, where $\|f\|^{2}=\iint_{I^{2}} \Delta\left(x_{1}, x_{2}\right)\left|f\left(x_{1}, x_{2}\right)\right|^{2} d x_{1} d x_{2}$ for any function $f$ which is square-integrable in $I^{2}$. Then putting $\Delta_{i}=$ $A_{i}^{\prime} B_{i}-A_{i} B_{i}^{\prime}\left({ }^{\prime}=d / d x_{i}\right)$ for $i=1,2$, we have from [4, Theorems 3.5, 4.3 and Subsection 4.4].

THEOREM 1. Suppose that $\Delta_{i}\left(x_{i}\right)$ vanishes identically in $0 \leqq x_{i} \leqq 1$ for $i=1,2$. Then the absolute values of the $\psi_{j, k}\left(x_{1}, x_{2}\right)$ for $\left(x_{1}, x_{2}\right) \in I^{2}$ remain less than some bound independent of $x_{1}, x_{2}, j$, and $k$.

We remark that this result is also true under much weaker 
conditions on the $A_{i}$ and $B_{i}$ than have been supposed here (see [4, $\S 1])$.

Our main concern in this paper will be the proof of the following theorem.

THeOREM 2. Suppose that for at least one $i, 1 \leqq i \leqq 2, \Delta_{i}\left(x_{i}\right)$ is not identically zero in $0 \leqq x_{i} \leqq 1$. Then the absolute values of the $(1+j+k)^{-1 / 3} \psi_{j, k}\left(x_{1}, x_{2}\right)$ for $\left(x_{1}, x_{2}\right) \in I^{2}$ remain less than some bound independent of $x_{1}, x_{2}, j$, and $k$.

It is important to observe from $[5, \S 6]$ that the exponent $1 / 3$ appearing in Theorem 2 is the best possible in the sense that if it is replaced by $1 / 3-\varepsilon, \varepsilon>0$, then the theorem may no longer be true.

2. Preliminaries. Before we can prove Theorem 2, we shall require some further information. Accordingly, let $P_{1}\left(x_{1}, \lambda, \mu\right)=$ $\lambda A_{1}\left(x_{1}\right)-\mu B_{1}\left(x_{1}\right), P_{2}\left(x_{2}, \lambda, \mu\right)=-\lambda A_{2}\left(x_{2}\right)+\mu B_{2}\left(x_{2}\right)$, and denote by $b_{1}$ and $b_{2}$ the infimum and supremum, respectively, of $A_{1}\left(x_{1}\right) / B_{1}\left(x_{1}\right)$ in $0 \leqq x_{1} \leqq 1$ and by $a_{1}$ and $a_{2}$ the infimum and supremum, respectively, of $A_{2}\left(x_{2}\right) / B_{2}\left(x_{2}\right)$ in $0 \leqq x_{2} \leqq 1$. Let $h_{1}(t)=\int_{0}^{1} P_{1}^{1 / 2}\left(x_{1}, 1, t\right) d x_{1}$ for $-\infty<$ $t<b_{1}, \quad h_{2}(t)=\int_{0}^{1} P_{2}^{1 / 2}\left(x_{2}, 1, t\right) d x_{2}$ for $a_{2}<t \stackrel{<}{<\infty}$, and $g(t)=h_{2}(t) / h_{1}(t)$ for $a_{2}<t<b_{1}$ (here and in the sequel it is always assumed that fractional powers of positive quantities have their positive values). Let $\delta=\left(b_{1}-a_{2}\right) / 100, t_{1}=a_{2}+\delta / 2, t_{2}=b_{1}-\delta / 2$, and $\theta_{i}=\tan ^{-1} g\left(t_{i}\right)$ for $i=1,2$, where the principal branch of the inverse tangent is taken. Note that $0<\theta_{1}<\theta_{2}<\pi / 2$. Let $\Omega$ denote the sector in the $(x, y)$-plane defined by the inequalities $\theta_{1} \leqq \theta \leqq \theta_{2}$ and $\Omega_{1}$ (resp. $\Omega_{2}$ ) the sector defined by $0 \leqq \theta<\theta_{1}$ (resp. $\theta_{2}<\theta \leqq \pi / 2$ ). Then guided by future requirements, we are now going to collect some facts concerning the behavior of the $\lambda_{j, k}$ and $\mu_{j, k}$ for $(j, k) \in \Omega_{1}$. To this end we first observe from [4, Eq. (4.2)] that there exists the positive numbers $M_{1}$ and $M_{2}$ such that

$$
M_{1}^{2}<\lambda_{j, k} / j^{2}<M_{2}^{2}
$$

when $(j, k) \in \Omega_{1}$ and $j$ is sufficiently large. Furthermore,

LeMmA 1. If $A_{2}\left(x_{2}\right)$ does not vanish identically in $0 \leqq x_{2} \leqq 1$, then $a_{1}<\eta_{j, 0}<\eta_{j, 1}<\cdots<\eta_{j, k^{*}}<a_{2}+\delta$ for all $j$ sufficiently large, where $\eta_{j, k}=\mu_{j, k} / \lambda_{j, k}$ and $k^{*}=k^{*}(j)$ denotes the greatest integer less than $j \tan \theta_{1}$.

Before proving the lemma let us collect some of the definitions 
and results given in $[4, \S 2]$. Recall that for each real $\lambda$, the totality of the values of $\mu$ for which (1) has a nontrivial solution satisfying (2) forms a countably infinite set of real numbers which we denoted by $\mu_{n}(\lambda), n \geqq 0$, where $\mu_{0}(\lambda)>\mu_{1}(\lambda)>\cdots, \mu_{n}(\lambda) \rightarrow-\infty$ as $n \rightarrow \infty$, $\phi_{1}\left(x_{1}, \lambda, \mu_{n}(\lambda)\right)$ has precisely $n$ zeros in $0<x_{1}<1$, and, for each $n$, $\mu_{n}(\lambda)$ is analytic in $-\infty<\lambda<\infty$ and satisfies here $b_{1} \leqq d \mu_{n}(\lambda) / d \lambda \leqq b_{2}$. Analogous definitions and results also held for the system (3-4), the analogue of $\mu_{n}(\lambda)$ being denoted by $\mu_{n}^{*}(\lambda)$, and it was remarked that $a_{1} \leqq d \mu_{n}^{*}(\lambda) / d \lambda \leqq a_{2}$ for $-\infty<\lambda<\infty$ and $n \geqq 0$. Recall also that when $\lambda$ ran from $-\infty$ to $\infty$, the $\mu_{n}(\lambda)$ (resp. $\mu_{n}^{*}(\lambda)$ ) determined disjoint analytic curves in the $(\lambda, \mu)$-plane which we denoted by $C_{n}$ (resp. $C_{n}^{*}$ ), and it was noted that when $j, k$ were any nonnegative integers, then $C_{j}$ intersected $C_{k}^{*}$ in precisely one point, namely at the eigenvalue of the system $(1-4),\left(\lambda_{j, k}, \mu_{j, k}\right)$.

Proof of Lemma 1. We shall henceforth assume that $j$ is large enough so as to ensure that $\mu_{j}(0)<\min \left\{0, \mu_{0}^{*}(0)\right\}$. Then in light of the preceding discussion it is clear that $\lambda_{j, k+1}>\lambda_{j, k}$ for $k \geqq 0$. We now assert that if $a_{1} \leqq t \leqq a_{2}+\delta$, then the equation $\mu_{j}(\lambda)=\lambda t$ ( $\lambda$ real) bas precisely one solution, and if we denote this solution by $\lambda(t)$ and put $\lambda^{*}=\lambda\left(a_{1}\right), \lambda^{\dagger}=\lambda\left(a_{2}+\delta\right)$, then $0<\lambda^{*} \leqq \lambda(t) \leqq \lambda$ and $\lambda(t)$ is a strictly increasing, continuous function of $t$. This assertion is easily proved by appealing to the implicit function theorem and to the fact that if $F(\lambda, t)=\mu_{j}(\lambda)-\lambda t$, then $F(0, t)<0$ and $F\left(\lambda_{2}, t\right)-$ $F\left(\lambda_{1}, t\right) \geqq\left(b_{1}-t\right)\left(\lambda_{2}-\lambda_{1}\right)>0$ for $\lambda_{2}>\lambda_{1}$. Hence it follows that $\mu_{j}(\lambda) / \lambda$ strictly increases as $\lambda$ runs from $\lambda^{*}$ to $\lambda^{*}$, assuming the value $a_{1}$ at $\lambda=\lambda^{*}$ and $a_{2}+\delta$ at $\lambda=\lambda^{\dagger}$.

To complete the proof of the lemma it remains only to show that $\lambda^{*}<\lambda_{j, 0}$ and $\lambda_{j, k^{*}}<\lambda^{*}$. To this end we may appeal to the results given in [6, Theorem 1] and to arguments similar to those used in [2, pp. 212-213] to establish that $a_{1}<\mu_{0}^{*}(\lambda) / \lambda<a_{2}$ for all large $\lambda$. Hence if $j$ is sufficiently large, then it follows from (5) and the discussion immediately preceding this proof that $a_{1}<$ $\mu_{j}\left(\lambda_{j, 0}\right) / \lambda_{j, 0}<a_{2}$, and the first inequality follows. Turning to the second inequality, we note from [4, Theorem 3.4] that $\eta_{j, k}{ }^{+}=t_{j, k}{ }^{\dagger}+$ $O\left(j^{-2}\right)$ as $j \rightarrow \infty$, where $k^{\dagger}=k^{\dagger}(j)$ denotes the smallest integer greater than or equal to $j \tan \theta_{1}, t_{j, k}{ }^{\dagger}$ denotes the point of $\left(a_{2}, b_{1}\right)$ at which $g(t)=\left(k^{+}+\nu_{2}\right) /\left(j+\nu_{1}\right)$, and, for $i=1,2, \nu_{i}$ denotes a constant satisfying $0 \leqq \nu_{i} \leqq 1$. Since $\left(1-j^{-1}\right) \tan \theta_{1}<g\left(t_{j, k}{ }^{\dagger}\right)<\tan \theta_{1}+2 j^{-1}$ for $j>1$, it therefore follows from the definition of $g$ (see also [4, Subsection 3.2]) that $t_{j, k}{ }^{\dagger}=t_{1}+O\left(j^{-1}\right)$, and hence $\eta_{j, k}{ }^{\dagger}=t_{1}+O\left(j^{-1}\right)$ as $j \rightarrow \infty$. Thus if $j$ is sufficiently large, then $a_{2}<\mu_{j}\left(\lambda_{j, k}{ }^{\dagger}\right) / \lambda_{j, k}{ }^{+}<a_{2}+\delta$, and the second inequality follows.

For later use we shall also need the following result (see [7, 
Theorem 3.1]). Here we denote by $D$ the class of continuously differentiable (complex-valued) functions on $0 \leqq s \leqq 1$.

Lemma 2. Given any $\varepsilon>0$, there is a $\gamma(\varepsilon)>0$ such that

$$
\int_{0}^{1}\left|f^{\prime}(s)\right|^{2} d s+\gamma(\varepsilon) \int_{0}^{1}|f(s)|^{2} d s \geqq \varepsilon|f(0)|^{2}
$$

for every $f(s) \in D$, where ${ }^{\prime}=d / d s$. This result also remains valid if in the right-hand side of the above equation we replace $f(0)$ by $f(1)$.

3. Proof of Theorem 2. We shall firstly introduce certain assumptions which will enable us to reduce our work somewhat.

Assumption 1. We shall henceforth suppose that $B_{i}\left(x_{i}\right)$ is constant in $0 \leqq x_{i} \leqq 1$ for $i=1,2$ and prove the theorem for this case only.

It is clear from [3, Eq. (20a), p. 292] that the proof of the theorem for the general case follows from this result.

Now we already know from [4, Theorem 3.5] that the absolute values of the $\psi_{j, k}\left(x_{1}, x_{2}\right)$ for $\left(x_{1}, x_{2}\right) \in I^{2}$ and $(j, k) \in \Omega$ remain less than some bound independent of $x_{1}, x_{2}, j$, and $k$, and hence it remains only to prove the assertion of Theorem 2 for $(j, k)$ in each of the sectors $\Omega_{1}$ and $\Omega_{2}$. However, since the proof for $(j, k) \in \Omega_{2}$ is similar to that for $(j, k) \in \Omega_{1}$, we shall only prove the assertion for this latter case. A further simplification of our work is again possible; for we know from [4, Theorem 4.3] and $[5, \S 6]$ that when $\Delta_{2}\left(x_{2}\right) \equiv 0$ (resp. $A_{2}\left(x_{2}\right) \neq 0$ ) in $0 \leqq x_{2} \leqq 1$, then the absolute values of the $\psi_{j, k}\left(x_{1}, x_{2}\right)$ (resp. $j^{-1 / 3} \psi_{j, k}\left(x_{1}, x_{2}\right)$ ) for $\left(x_{1}, x_{2}\right) \in I^{2}$ and $(j, k) \in \Omega_{1}$ remain less than some bound independent of $x_{1}, x_{2}, j$, and $k$. Thus it is clear that it remains only to verify the assertion of the theorem under the following hypotheses.

Assumption 2. We shall assume from now on that $a_{1}<a_{2}$, that $\Delta_{2}\left(x_{2}\right)$ vanishes in $0 \leqq x_{2} \leqq 1$, and that $(j, k) \in \Omega_{1}$.

Let $u_{j, k}\left(x_{1}\right)=\phi_{1}\left(x_{1}, \lambda_{j, k}, \mu_{j, k}\right) / J_{1}(j, k)$ and $v_{j, k}\left(x_{2}\right)=\phi_{2}\left(x_{2}, \lambda_{j, k}, \mu_{j, k}\right) / J_{2}(j, k)$, where $J_{i}(j, k)=\left(\int_{0}^{1} \phi_{i}^{2}\left(x_{i}, \lambda_{j, k}, \mu_{j, k}\right) d x_{i}\right)^{1 / 2}$ for $i=1,2$. Then in light of (5) and Lemma 1, we may argue precisely as we did in [4, Theorem 4.3] to verify that the absolute values of the $u_{j, k}\left(x_{1}\right)$ for $0 \leqq x_{1} \leqq 1$ remain less than some bound independent of $x_{1}, j$, and $k$. Thus in order to complete the proof of Theorem 2 it remains only to prove the following assertion.

Proposition 1. It is the case that the absolute values of the 
$j^{-1 / 3} v_{j, k}\left(x_{2}\right)$ for $0 \leqq x_{2} \leqq 1$ remain less than some bound independent of $x_{2}, j$, and $k$.

Before passing to the proof of Proposition 1, let us simplify our notation by henceforth dropping subscripts and writing $x$ for $x_{2}, A$ for $A_{2}, B$ for $B_{2}, P$ for $P_{2}$, and $q$ for $q_{2}$. Putting $r(x)=A(x) / B(x)$, let $0 \leqq x_{1}^{*}<x_{2}^{*}<\cdots<x_{p}^{*} \leqq 1, p \geqq 1$, denote the critical points of $r(x)$ in $0 \leqq x \leqq 1, m_{i}(\geqq 2)$ the order of the zero of $r(x)-r\left(x_{i}^{*}\right)$ at $x_{i}^{*}$, and let $R_{i}=r^{\left(m_{i}\right)}\left(x_{i}^{*}\right)$, where ${ }^{(n)}=d^{n} / d x^{n}$. Choose the positive constant $d^{\sharp}$ small enough so that $d^{\sharp}<\min \left\{\left(x_{i+1}^{*}-x_{i}^{*}\right) / 100\right\}, 1 \leqq i \leqq$ $p-1$, if $p>1, d^{\sharp}<x_{1}^{*} / 100$ if $x_{1}^{*}>0$, and $d^{\sharp}<\left(1-x_{p}^{*}\right) / 100$ if $x_{p}^{*}<1$. Put $x_{0}^{*}=0, x_{p+1}^{*}=1$, and let $c^{*}$ be a positive number chosen small enough so that if $0 \leqq m<n \leqq p+1$ and $r\left(x_{m}^{*}\right) \neq r\left(x_{n}^{*}\right)$, then $\left|r\left(x_{m}^{*}\right)-r\left(x_{n}^{*}\right)\right| \geqq c^{*}$. Let $c$ be a positive number not exceeding $c^{*} / 100$ choosen small enough so that $c \leqq\left|r\left(x_{i}^{*} \pm d^{\sharp}\right)-r\left(x_{i}^{*}\right)\right|$ for $i=0, \cdots,(p+1)$, where, of course, only the + or - sign is taken if $x_{i}^{*}$ is an end point of the interval $[0,1]$. If $1 \leqq i \leqq p$ and $0<$ $x_{i}^{*}<1$, then let $E_{i}$ and $E_{i}^{*}$ denote the intervals $x_{i}^{*}-d_{i}^{-}<x<x_{i}^{*}+d_{i}^{+}$ and $x_{i}^{*}-d_{i}^{-} / 2<x<x_{i}^{*}+d_{i}^{+} / 2$, respectively, where the $x_{i}^{*} \pm d_{i}^{ \pm}$denote the points of $\left[x_{i}^{*}-d^{\#}, x_{i}^{*}+d^{*}\right]$ satisfying $\left|r\left(x_{i}^{*} \pm d_{i}^{ \pm}\right)-r\left(x_{i}^{*}\right)\right|=c$. If $i=1$ (resp. $i=p$ ) and $x_{i}^{*}=0$ (resp. $x_{p}^{*}=1$ ), then let $E_{1}, E_{1}^{*}$ (resp. $E_{p}, E_{p}^{*}$ ) denote the intervals $0 \leqq x<d_{1}^{+}, 0 \leqq x<d_{1}^{+} / 2$ (resp. $1-d_{p}^{-}<x \leqq 1,1-d_{p}^{-} / 2<x \leqq 1$ ), respectively, where $d_{1}^{+}$(resp. $1-d_{p}^{-}$) denotes the point of $\left[0, d^{\sharp}\right]$ (resp. $\left[1-d^{\sharp}, 1\right]$ ) satisfying $\left|r\left(d_{1}^{+}\right)-r(0)\right|=c$ (resp. $\left.\left|r\left(1-d_{p}^{-}\right)-r(1)\right|=c\right)$. If $x_{1}^{*}>0$ (resp. $\left.x_{p}^{*}<1\right)$, then let $E_{0}$ (resp. $E_{p+1}$ ) denote the interval $0 \leqq x<d_{0}^{+}$(resp. $1-d_{p+1}^{-}<x \leqq 1$ ), where $d_{0}^{+}$(resp. $1-d_{p+1}^{-}$) denotes the point of $\left[0, d^{\sharp}\right]$ (resp. $\left[1-d^{\sharp}, 1\right]$ ) satisfying $\left|r\left(d_{\nu}^{+}\right)-r(0)\right|=c$ (resp. $\left.\left|r\left(1-d_{p+1}^{-}\right)-r(1)\right|=c\right)$. If $x_{1}^{*}=0$ (resp. $x_{p}^{*}=1$ ), then put $d_{0}^{+}=d_{1}^{+}$and $E_{0}=E_{1}$ (resp. $d_{p+1}^{-}=d_{p}^{-}$and $\left.E_{p+1}=E_{p}\right)$. Finally, let $N$ denote the infimum of $\left|r^{(1)}(x)\right|$ in $[0,1]-$ $\bigcup_{i=1}^{p} E_{i}^{*}, 2 d$ the minimum of the $d_{i}^{ \pm}, 0 \leqq i \leqq p+1, Q$ the supremum of $|q(x)|$ in $[0,1]$, and put $b=B(x), \varepsilon_{0}=\left|\cot \alpha_{2}\right|$ if $\alpha_{2}>\pi / 2$ (see (4)), $\varepsilon_{0}=0$ if $\alpha_{2} \leqq \pi / 2, \varepsilon_{1}=\cot \beta_{2}$ if $\beta_{2}<\pi / 2$, and $\varepsilon_{1}=0$ if $\beta_{2} \geqq \pi / 2$.

Assumption 3. We shall assume from now on that $j$ exceeds

$$
10^{3}\left[\left(1+M^{*}\right)\left(\varepsilon_{0}+\varepsilon_{1}+Q^{2}+Q^{1 / 2}+\delta^{-1}+c^{-1}+(N+1) / N d\right)\right]^{3 / 2}
$$

and is large enough to satisfy the assertions of both (5) and Lemma 1 , where $M^{*}=\left(b M_{1}^{2}\right)^{-1 / 2}$ and $\delta$ is defined at the beginning of $\S 2$.

Proof of Proposition 1. Let us fix $(j, k)$ and for simplicity of notation write $\lambda, \eta, v(x)$, and $P(x)$ for $b \lambda_{j, k}, \eta_{j, k}, v_{j, k}(x)$, and $P\left(x, \lambda_{j, k}, \mu_{j, k}\right)$, respectively. We are now going to prove that 


$$
U=\int_{0}^{1}\left(v^{\prime}(x)\right)^{2} d x \leqq K^{*} \lambda \text { and } v^{2}(x) \leqq K^{*} \lambda
$$

for $0 \leqq x \leqq 1$, where ${ }^{\prime}=d / d x$ and $K^{*}$ denotes a positive constant independent of $x, j$, and $k$. To this end we first argue with (3) and (4) to show that

$$
U \leqq \int_{0}^{1}|P+q| v^{2} d x+\varepsilon_{0} v^{2}(0)+\varepsilon_{1} v^{2}(1),
$$

where the $\varepsilon_{i}$ are defined in the preceding paragraph. If $\varepsilon_{0}>0$, then it follows from Lemma 2 (with $\varepsilon=4 \varepsilon_{0}$ ) that $\varepsilon_{0} v^{2}(0) \leqq\left(U+\gamma\left(4 \varepsilon_{0}\right)\right) / 4$, with a similar result holding for $\varepsilon_{1} v^{2}(1)$ if $\varepsilon_{1}>0$. In light of (5) and Lemma 1 , the assertion concerning $U$ follows immediately. The second inequality in (6) also follows easily if we observe from Lemma 2 that $v^{2}(0) \leqq U+\gamma(1)$. Next we may argue with the above bound for $U$ as in [3, pp. 334-335] to show that $\left|\left(v^{\prime}(x)\right)^{2}+P(x) v^{2}(x)\right| \leqq$ $K^{2} \lambda$ for $0 \leqq x \leqq 1$, where $K$ denotes a positive constant independent of $x, j$, and $k$. From these results we draw the following

\section{CONCLUSIONS.}

1. If $\eta-r(x) \geqq j^{-2 / 3}$, then $|v(x)| \leqq K j^{1 / 3}$.

2. If $\eta-r(x) \geqq-2 Q / \lambda$ (i.e., if $P(x) \geqq-2 Q$ ), then $\left|v^{\prime}(x)\right| \leqq K^{\sharp} j$, where $K^{\sharp}(\geqq 1)$ denotes a constant independent of $x, j$, and $k$.

3. If $\alpha_{2}>\pi / 2$ and $r(0)-\eta \geqq j^{-2 / 3}$, then $0<v(0) \leqq K^{\sharp} j^{1 / 3}$.

4. If $\beta_{2}<\pi / 2$ and $r(1)-\eta \geqq j^{-2 / 3}$, then $|v(1)| \leqq K^{\sharp} j^{1 / 3}$.

5. If $0 \leqq x_{1}<x_{2} \leqq 1$, if $J=\left\{x \mid x_{1} \leqq x \leqq x_{2}\right\}$, and if $P(x)+q(x) \geqq 0$ for $x \in J$, then $|v(x)|<\left|v\left(x_{2}\right)\right|+3 K^{\sharp} j^{1 / 3}$ for $x \in J$.

6. If $0 \leqq x_{1}<x_{2} \leqq 1$, if $J=\left\{x \mid x_{1} \leqq x \leqq x_{2}\right\}$, and if $P(x) \geqq-2 Q$ for $x \in J$, then there is an $\xi \in J$ such that $\left|v^{\prime}(\xi)\right|<3 K^{\#} j^{1 / 3}\left(x_{2}-x_{1}\right)^{-1}$.

7. If $0 \leqq x_{1} \leqq 1-j^{-2 / 3}$, if $J=\left\{x \mid x_{1} \leqq x \leqq x_{1}+j^{-2 / 3}\right\}$, if $P\left(x_{1}\right) \geqq$ $-2 Q$, and if $P(x)+q(x) \leqq 0$ for $x \in J$, then $\left|v\left(x_{1}\right)\right|<3 K^{\sharp} j^{1 / 3}$.

Conclusions 1-4 follow immediately from the foregoing discussion and (5). Conclusions 5-7 are not obvious. However in order not to impair the continuity of the proof, we shall not elaborate upon them until the final stage of the proof.

We are now going to utilize the above information to investigate the behaviour of $v(x)$ and $P(x)+q(x)$ in various subintervals of $[0,1]$. The proof of Proposition 1 will then follow from these results.

Case 1. Suppose that $x_{0} \in[0,1]-\bigcup_{n=0}^{p+1} E_{n}$ and $\eta=r\left(x_{0}\right)$. We note that for this case $x_{i}^{*}<x_{0}<x_{i+1}^{*}$ for some $i, 0 \leqq i \leqq p$. Now let $x_{1}$ and $x_{2}$ denote the points of the interval $\left(x_{0}-d, x_{0}+d\right)$ at 
which $r(x)=\eta+Q / \lambda$ and $r(x)=\eta-j^{-2 / 3}$, respectively, and assume firstly that $r^{\prime}\left(x_{0}\right)<0$. Then $\left(x_{2}-x_{1}\right)<2 N^{-1} j^{-2 / 3}$ and from conclusions 1 and 2 above we also have $\left|v\left(x_{2}\right)\right| \leqq K j^{1 / 3}$ and $\left|v^{\prime}(x)\right| \leqq K^{\#} j$ in $x_{1} \leqq$ $x \leqq x_{2}$. Hence $|v(x)|<K_{1} j^{1 / 3}$ for $x_{1} \leqq x \leqq x_{i+1}^{*}$ and $P(x)+q(x)<0$ for $x_{i}^{*} \leqq x<x_{1}$, where $K_{1}=K+2 N^{-1} K^{\sharp}$. Similarly, if $r^{\prime}\left(x_{0}\right)>0$, then $|v(x)|<K_{1} j^{1 / 3}$ for $x_{i}^{*} \leqq x \leqq x_{1}$ and $P(x)+q(x)<0$ for $x_{1}<x \leqq x_{i+1}^{*}$.

Case 2. Suppose that for some $i, 1 \leqq i \leqq p, 0<x_{i}^{*}<1, m_{i}$ is even, and $R_{i}>0$ (see the paragraph following the statement of Proposition 1 for terminology). For simplicity of notation let us write $x^{*}$ for $x_{i}^{*}$ and assume firstly that $2 Q / \lambda \leqq \eta-r\left(x^{*}\right)<c$. Let $x_{1}$ and $x_{2}$ denote the points of the interval $\left(x^{*}, x^{*}+d_{i}^{+}+d\right)$ at which $r(x)=\eta-Q / \lambda$ and $r(x)=\eta+Q / \lambda$, respectively. Then $P(x)+q(x)$ is positive in $\left[x^{*}, x_{1}\right)$, negative in $\left(x_{2}, x_{i+1}^{*}\right]$, and $-Q \leqq P(x) \leqq Q$ for $x_{1} \leqq x \leqq x_{2}$. Hence it follows from Conclusions 5-7 that $|v(x)|<$ $\left|v\left(x_{1}\right)\right|+K_{2} j^{1 / 3}$ for $x^{*} \leqq x \leqq x_{1},\left|v\left(x_{2}\right)\right|<K_{2} j^{1 / 3}$, and there is an $\xi$, $x_{1} \leqq \xi \leqq x_{2}$, such that

$$
\left|v^{\prime}(\xi)\right|<K_{2} j^{1 / 3} /\left(x_{2}-x_{1}\right),
$$

where $K_{2}=K+3 K^{\sharp}$. Since we may argue with (3) as in [8, p. 167] to show that

$$
\left|v(x)-v(\xi)-v^{\prime}(\xi)(x-\xi)\right| \leqq 4 Q\left(x_{2}-x_{1}\right)^{3 / 2} / 3, \quad x_{1} \leqq x \leqq x_{2},
$$

we therefore conclude that $|v(x)|<6 K_{2} j^{1 / 3}$ for $x^{*} \leqq x \leqq x_{2}$ and $P(x)+$ $q(x)<0$ for $x_{2}<x \leqq x_{i+1}^{*}$. Similarly we can show that $|v(x)|<6 K_{2} j^{1 / 3}$ for $x_{2}^{\dagger} \leqq x \leqq x^{*}$ and $P(x)+q(x)<0$ for $x_{i-1}^{*} \leqq x<x_{2}^{\dagger}$, where $x_{2}^{\dagger}$ denotes the point of the interval $\left(x^{*}-d_{i}^{-}-d, x^{*}\right)$ at which $r(x)=\eta+Q / \lambda$.

Assume next that $-Q / \lambda<\eta-r\left(x^{*}\right)<2 Q / \lambda$ and denote by $x_{1}$ the point of the interval $\left(x^{*}, x^{*}+d_{i}^{+}\right)$at which $r(x)=\eta+Q / \lambda$. Then $-Q \leqq P(x)<2 Q$ for $x^{*} \leqq x \leqq x_{1}$ and $P(x)+q(x)<0$ for $x_{1}<$ $x \leqq x_{i+1}^{*}$. From Conclusions 6 and 7 it follows that $\left|v\left(x_{1}\right)\right|<K_{2} j^{1 / 3}$ and that there is an $\xi, x^{*} \leqq \xi \leqq x_{1}$, such that

$$
\left|v^{\prime}(\xi)\right|<K_{2} j^{1 / 3} /\left(x_{1}-x^{*}\right) \text {. }
$$

Since

$$
\left|v(x)-v(\xi)-v^{\prime}(\xi)(x-\xi)\right| \leqq 2 Q\left(x_{1}-x^{*}\right)^{3 / 2}, \quad x^{*} \leqq x \leqq x_{1},
$$

we therefore conclude that $|v(x)|<5 K_{2} j^{1 / 3}$ for $x^{*} \leqq x \leqq x_{1}$. Similarly we can show that $|v(x)|<5 K_{2} j^{1 / 3}$ for $x_{1}^{\dagger} \leqq x \leqq x^{*}$ and $P(x)+q(x)<0$ for $x_{i-1}^{*} \leqq x<x_{1}^{\dagger}$, where $x_{1}^{\dagger}$ denotes the point of the interval $\left(x^{*}-d_{i}^{-}, x^{*}\right)$ at which $r(x)=\eta+Q / \lambda$.

Finally, if $\eta \leqq r\left(x^{*}\right)-Q / \lambda$, then $P(x)+q(x) \leqq 0$ for $x_{i-1}^{*} \leqq x \leqq$ $x_{i+1}^{*}$. 
Case 3. Suppose that for some $i, 1 \leqq i \leqq p, 0<x_{i}^{*}<1, m_{i}$ is even, and $R_{i}<0$. Writing $x^{*}$ for $x_{i}^{*}$, let us assume firstly that $-c<\eta-r\left(x^{*}\right) \leqq-2 Q / \lambda$. Let $x_{1}, x_{2}$, and $x_{3}$ denote the points of the interval $\left(x^{*}, x^{*}+d_{i}^{+}+d\right)$ at which $r(x)=\eta+Q / \lambda, r(x)=\eta-Q / \lambda$, and $r(x)=\eta-j^{-2 / 3}$, respectively. Then $-Q \leqq P(x) \leqq Q$ for $x_{1} \leqq$ $x \leqq x_{2}$ and it is easy to see from Conclusions 1, 5, and 6 that $|v(x)|<K_{2} j^{1 / 3}$ for $x_{2} \leqq x \leqq x_{3}$ and that (7) is valid for some $\xi$ in $\left[x_{1}, x_{2}\right]$. In light of (8) we conclude that $|v(x)|<5 K_{2} j^{1 / 3}$ for $x_{1} \leqq$ $x \leqq x_{i+1}^{*}$ and $P(x)+q(x)<0$ for $x^{*} \leqq x<x_{1}$. Similarly we can show that $|v(x)|<5 K_{2} j^{1 / 3}$ for $x_{i-1}^{*} \leqq x \leqq x_{1}^{\dagger}$ and $P(x)+q(x)<0$ for $x_{1}^{\dagger}<$ $x \leqq x^{*}$, where $x_{1}^{\dagger}$ denotes the point of the interval $\left(x^{*}-d_{i}^{-}, x^{*}\right)$ at which $r(x)=\eta+Q / \lambda$.

Assume next $-2 Q / \lambda<\eta-r\left(x^{*}\right)<Q / \lambda$ and denote by $x_{1}$ and $x_{2}$ the points of the interval $\left(x^{*}, x^{*}+d_{i}^{+}\right)$at which $r(x)=\eta-Q / \lambda$ and $r(x)=\eta-j^{-2 / 3}$, respectively. Then $-2 Q<P(x) \leqq Q$ for $x^{*} \leqq x \leqq x_{1}$ and it is easy to see from Conclusions 1, 5, and 6 that $|v(x)|<K_{2} j^{1 / 3}$ in $x_{1} \leqq x \leqq x_{2}$ and that (9) is valid for some $\xi$ in $\left[x^{*}, x_{1}\right]$. Hence we conclude from (10) that $|v(x)|<5 K_{2} j^{1 / 3}$ for $x^{*} \leqq x \leqq x_{i+1}^{*}$. Similarly we can show that $|v(x)|<5 K_{2} j^{1 / 3}$ for $x_{i-1}^{*} \leqq x \leqq x^{*}$.

Finally if $\eta \geqq r\left(x^{*}\right)+Q / \lambda$, then we may argue with Conclusions 1 and 5 above to show that $|v(x)|<K_{2} j^{1 / 3}$ for $x_{i-1}^{*} \leqq x \leqq x_{i+1}^{*}$.

Case 4. Suppose that $x_{1}^{*}=0$ and $R_{1}>0$. Then it follows from Case 2 above that if $-Q / \lambda<\eta-r(0)<c$, then $|v(x)|<6 K_{2} j^{1 / 3}$ for $0 \leqq x \leqq x_{1}$ and $P(x)+q(x)<0$ for $x_{1}<x \leqq x_{2}^{*}$, where $x_{1}$ denotes the point of the interval $\left(0, d_{1}^{+}+d\right)$ at which $r(x)=\eta+Q / \lambda$. If $\eta \leqq$ $r(0)-Q / \lambda$, then $P(x)+q(x) \leqq 0$ for $0 \leqq x \leqq x_{2}^{*}$ and we see from Conclusion 3 above that the only further problem which requires investigation here occurs when $-j^{-2 / 3}<\eta-r(0) \leqq-Q / \lambda$ and $\alpha_{2}>\pi / 2$. Accordingly, fixing our attention upon this situation and observing that $v(0)>0$, let us firstly suppose that $v(x)>0$ in $0 \leqq x \leqq j^{-2 / 3}$. Then it follows from (3), (4), and Assumption 3 that in this interval $v^{\prime}(x) \geqq v(0) \cot \alpha_{2}, \quad v(x)>v(0) / 2$, and hence we conclude from the equation

$$
\int_{0}^{1} v^{2}(x) d x=1
$$

that $v(0)<2 j^{1 / 3}$. Similar arguments also show that $v(x)$ cannot vanish in $\left[0, j^{-2 / 3}\right]$.

Case 5. Suppose that $x_{1}^{*}=0$ and $R_{1}<0$. Then it follows from Case 3 above that $|v(x)|<5 K_{2} j^{1 / 3}$ for $0 \leqq x \leqq x_{2}^{*}$ if $\eta>r(0)-2 Q / \lambda$. If $-c<\eta-r(0) \leqq-2 Q / \lambda$, then $|v(x)|<5 K_{2} j^{1 / 3}$ for $x_{1} \leqq x \leqq x_{2}^{*}, P(x)+$ $q(x)<0$ for $0 \leqq x<x_{1}$ (where $x_{1}$ denotes the point of the interval 
$\left(0, d_{1}^{+}\right)$at which $\left.r(x)=\eta+Q / \lambda\right)$, and the only further problem which requires investigation here occurs when $-j^{-2 / 3}<\eta-r(0) \leqq-2 Q / \lambda$ and $\alpha_{2}>\pi / 2$ (see Conclusion 3 above). However, for this situation we may argue as in Case 4 above to show that $v(0)<2 j^{1 / 3}$ if $x_{1} \geqq j^{-2 / 3}$ and $v(0)<2 v\left(x_{1}\right)<10 K_{2} j^{1 / 3}$ otherwise (recall that $v(0)>0$ ).

Case 6. Suppose that $x_{1}^{*}>0$. Then the results of Case 4 (resp. Case 5) above, with $d_{1}^{+}$and $x_{2}^{*}$ replaced by $d_{0}^{+}$and $x_{1}^{*}$, respectively, remain valid for this case if $r^{\prime}(0)>0$ (resp. $r^{\prime}(0)<0$ ).

Finally, results analogous to those above hold for $v(x)$ and $P(x)+q(x)$ in the intervals $\left[x_{p-1}^{*}, 1\right]$ if $x_{p}^{*}=1,\left[x_{p}^{*}, 1\right]$ if $x_{p}^{*}<1$, and $\left[x_{i-1}^{*}, x_{i+1}^{*}\right]$ if $1 \leqq i \leqq p, 0<x_{i}^{*}<1$, and $m_{i}$ is odd. The proof of Proposition 1 is then completed by appealing to Lemma 1 and to the fact that if $0 \leqq x_{1}<x_{2} \leqq 1$ and $P(x)+q(x) \leqq 0$ in $\left[x_{1}, x_{2}\right]$, then in this interval $v(x) v^{\prime}(x)$ is monotonic increasing and $|v(x)| \leqq \max \left\{\left|v\left(x_{1}\right)\right|\right.$, $\left.\left|v\left(x_{2}\right)\right|\right\}$.

We now fulfill a commitment made earlier to explain in greater detail how Conclusions 5-7 were arrived at. Accordingly, let us firstly fix our attention upon Conclusion 5, assume that $|v(x)|$ attains its absolute maximum in $J$ at the point $x_{0}$, and put $v_{0}=v\left(x_{0}\right), v_{2}=$ $v\left(x_{2}\right)$. It is clear that we need only consider the case $\left|v_{0}\right|>\left|v_{2}\right|$. Suppose firstly that $v(x)>0$ for $x \in J$. Then

$$
v(x) \geqq v_{2}+\left(v_{0}-v_{2}\right)\left(x_{2}-x\right) /\left(x_{2}-x_{0}\right)
$$

for $x_{0} \leqq x \leqq x_{2}$, and hence it follows from (11) that $\left(v_{0}-v_{2}\right)^{2}\left(x_{2}-x_{0}\right)<3$. On the other hand we see from Conclusion 2 that $v_{0}-v_{2} \leqq K^{\sharp} j\left(x_{2}-x_{0}\right)$, and so Conclusion 5 follows for this case. If $v(x)$ vanishes in $J$ or if $v(x)<0$ for $x \in J$, then Conclusion 5 is arrived at by using similar arguments.

Turning next to Conclusion 6, assume that $\left|v^{\prime}(x)\right| \geqq \gamma=$ $3 K^{\sharp} j^{1 / 3} /\left(x_{2}-x_{1}\right)$ for $x \in J$. Then a simple integration shows that for $x \in J, \gamma^{-1}|v(x)|$ exceeds $\left(x-x_{1}\right)$ if $v(x) v^{\prime}(x)>0$ for all $x$ in $J$, exceeds $\left(x_{2}-x\right)$ if $v(x) v^{\prime}(x)<0$ for all $x$ in $J$, and is not less than $\left|x-x_{0}\right|$ if $x_{0} \in J$ and $v\left(x_{0}\right)=0$. Hence it follows from (11) that $\left(3 K^{\sharp} j^{1 / 3}\right)^{2}\left(x_{2}\right.$ $\left.x_{1}\right)<24$, and since $\gamma \leqq K^{\sharp} j$ (see Conclusion 2), we arrive at the contradiction that $27\left(K^{\sharp}\right)^{2}<24$.

Fixing our attention lastly upon Conclusion 7 , assume that $v_{1}=$ $v\left(x_{1}\right) \geqq 3 K^{\sharp} j^{1 / 3}$. If $v^{\prime}\left(x_{1}\right) \geqq 0$, then it follows from (3) that $v(x) \geqq v_{1}$ for $x \in J$, and hence we conclude from (11) that $\left(3 K^{\sharp}\right)^{2}<1$, which is a contradiction. Suppose next that $v^{\prime}\left(x_{1}\right)<0$ and $v(x)>0$ for $x \in J$. Then $v^{\prime}(x) \geqq-K^{\sharp} j$ (see Conclusion 2) and $v(x) \geqq 2 K^{\sharp} j^{1 / 3}$ for $x \in J$, and hence it follows from (11) that $\left(2 K^{\sharp}\right)^{2}<1$, which again is a 
contradiction. If $v^{\prime}\left(x_{1}\right)<0$, if $x_{1}<x_{0} \leqq x_{1}+j^{-2 / 3}$, if $v(x)>0$ for $x_{1} \leqq x<x_{0}$, and if $v\left(x_{0}\right)=0$, then $v^{\prime}(x) \geqq-K^{\sharp} j$ for $x_{1} \leqq x \leqq x_{0}$, and hence we arrive at the contradiction that $v_{1} \leqq K^{\sharp} j^{1 / 3}$. Similarly we can show that the supposition $v_{1} \leqq-3 K^{\sharp} j^{1 / 3}$ is untenable.

\section{REFERENCES}

1. F. V. Atkinson, Multiparameter spectral theory, Bull. Amer. Math. Soc., 74 (1968), 1-27.

2. E. A. Coddington and N. Levinson, Theory of Ordinary Differential Equations, McGraw-Hill, New York, 1955.

3. R. Courant and D. Hilbert, Methods of Mathematical Physics, Vol. 1, Interscience, New York, 1965.

4. M. Faierman, On the distribution of the eigenvalues of a two-parameter system of ordinary differential equations of the second order, SIAM J. Math. Anal., 8 (1977), 854-870.

5. - Distribution of eigenvalues of a two-parameter system of differential equations, Trans. Amer. Math. Soc., 247 (1979), 45-86.

6. - Asymptotic formulae for the eigenvalues of a two-parameter system of ordinary differential equations of the second order, Canad. Math. Bull., 17 (1975), $657-665$.

7. - An oscillation theorem for a one-parameter ordinary differential equation of the second order, J. Differential Equations, 11 (1972), 10-37.

8. E. C. Titchmarsh, Eigenfunction Expansions Associated with Second-order Differential Equations, Part I, 2nd ed., Clarendon Press, Oxford, 1962.

Received October 27, 1976 and in revised form October 2, 1979.

UNIVERSITY OF THE WITWATERSRAND,

JoHANNESBURG, SOUTH AFrica 



\section{PACIFIC JOURNAL OF MATHEMATICS}

\section{EDITORS}

DONALD BABBITT (Managing Editor)

University of California

Los Angeles, CA 90024

Hugo RossI

University of Utah

Salt Lake City, UT 84112

C. C. MOORE and ANDREW OGG

University of California

Berkeley, CA 94720

\section{J. DugunduI}

Department of Mathematics

University of Southern California

Los Angeles, CA 90007

R. Finn and J. Milgram

Stanford University

Stanford, CA 94305

\section{ASSOCIATE EDITORS}
E. F. BeCKenBACH
B. H. NeumanN
F. WOLF
K. YosHIDA

\section{SUPPORTING INSTITUTIONS}

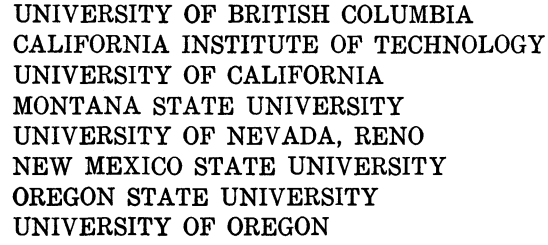

UNIVERSITY OF BRITISH COLUMBIA CALIFORNIA INSTITUTE OF TECHNOLOGY UNIVERSITY OF CALIFORNIA

MONTANA STATE UNIVERSITY

UNIVERSITY OF NEVADA, RENO

NEW MEXICO STATE UNIVERSITY

OREGON STATE UNIVERSITY UNIVERSITY OF OREGON

\author{
UNIVERSITY OF SOUTHERN CALIFORNIA \\ STANFORD UNIVERSITY \\ UNIVERSITY OF HAWAII \\ UNIVERSITY OF TOKYO \\ UNIVERSITY OF UTAH \\ WASHINGTON STATE UNIVERSITY \\ UNIVERSITY OF WASHINGTON
}

The Supporting Institutions listed above contribute to the cost of publication of this Journal, but they are not owners or publishers and have no responsibility for its content or policies.

Mathematical papers intended for publication in the Pacific Journal of Mathematics should be in typed form or offset-reproduced, (not dittoed), double spaced with large margins. Please do not use built up fractions in the text of the manuscript. However, you may use them in the displayed equations. Underline Greek letters in red, German in green, and script in blue. The first paragraph or two must be capable of being used separately as a synopsis of the entire paper. Please propose a heading for the odd numbered pages of less than 35 characters. Manuscripts, in triplicate, may be sent to any one of the editors. Please classify according to the scheme of Math. Reviews, Index to Vol. 39. Supply name and address of author to whom proofs should be sent. All other communications should be addressed to the managing editor, or Elaine Barth, University of California, Los Angeles, California, 90024.

50 reprints to each author are provided free for each article, only if page charges have been substantially paid. Additional copies may be obtained at cost in multiples of 50 .

The Pacific Journal of Mathematics is issued monthly as of January 1966. Regular subscription rate: $\$ 84.00$ a year (6 Vols., 12 issues). Special rato: $\$ 42.00$ a year to individual members of supporting institutions.

Subscriptions, orders for numbers issued in the last three calendar years, and changes of address shoud be sent to Pacific Journal of Mathematics, P.O. Box 969, Carmel Valley, CA 93924, U.S.A Old back numbers obtainable from Kraus Periodicals Co., Route 100, Millwood, NY 10546.

PUBLISHED BY PACIFIC JOURNAL OF MATHEMATICS, A NON-PROFIT CORPORATION

Printed at Kokusai Bunken Insatsusha (International Academic Printing Co., Ltd.). 8-8, 3-chome, Takadanobaba, Shinjuku-ku, Tokyo 160, Japan.

Copyright (C) 1980 by Pacific Jounal of Mathematics Manufactured and first issued in Japan 


\section{Pacific Journal of Mathematics \\ Vol. 90, No. $2 \quad$ October, 1980}

Frank Hayne Beatrous, Jr., Hölder estimates for the $\bar{\partial}$ equation with a support condition ..................................... 249

Charles L. Belna, Michael Jon Evans and Paul Humke, Planar continua

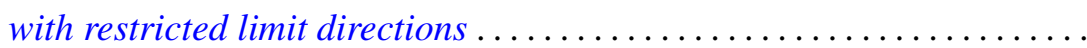

Leon Brown and Takashi Ito, Classes of Banach spaces with unique isometric preduals................................. 261

V. K. Deshpande, Completions of Noetherian hereditary prime rings ..... . 285

Deepak Dhar, Asymptotic enumeration of partially ordered sets . . . . . . . 299

Zeev Ditzian, On interpolation of $L_{p}[a, b]$ and weighted Sobolev

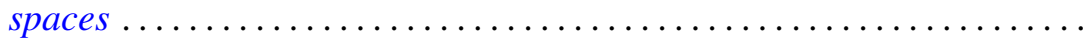

Andrew George Earnest, Congruence conditions on integers represented by

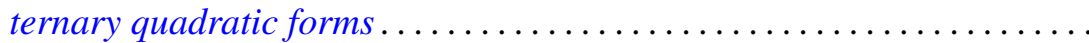

Melvin Faierman, Bounds for the eigenfunctions of a two-parameter system of ordinary differential equations of the second order ..............

Hector O. Fattorini, Vector-valued distributions having a smooth

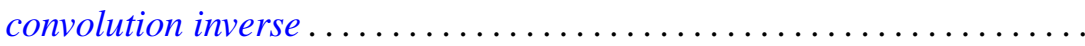

Howard D. Fegan, The spectrum of the Laplacian on forms over a Lie

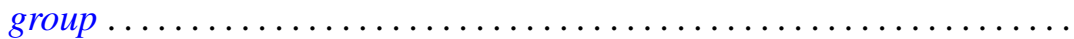

Gerald Leonard Gordon, On the degeneracy of a spectral sequence associated to normal crossings..

S. Madhavan, On bisimple weakly inverse semigroups ... 397

Françoise Mathot, On the decomposition of states of some

Roger McCann, Embedding asymptotically stable dynamical systems into radial flows in $l_{2}$

Michael L. Mihalik, Ends of fundamental groups in shape and proper homotopy...............................

Samuel Murray Rankin, III, Boundary value problems for partial functional differential equations .

Randy Tuler, Arithmetic sums that determine linear characters on $\Gamma(N)$

Jeffrey D. Vaaler, On linear forms and Diophantine approximation ..

G. P. Wene, Alternative rings whose symmetric elements are nilpotent or a right multiple is a symmetric idempotent. . 